\title{
A survey of critical care nursing education in Europe
}

Birte Baktoft, RN, CCN, Clinical Nursing Teacher, Randers Hospital, Aarhus, Denmark

Elio Drigo, Italy Maria Luisa Hohl, Switzerland Slavica Klancar, Slovenia Maria Tseroni, Greece *

Piroska Putzai, Hungary

All authors were members of the European Federation of Critical Care Nursing Associations Council during the preparation of this paper University of Wolverhampton, UK

e-mail: birte.baktoft@teliamail.dk

Key words: critical care curriculum * education qualification specialist

\section{INTRODUCTION}

When the European Federation of Critical Care Nursing Associations (EfCCNa) was founded in 1997, one of its first tasks was to establish sub-committees to work on the different objectives set by EfCCNa. One of the areas, where EfCCNa felt there was little information, was that of critical care educational standards within its member countries.

In terms of global travel and communication, the world has become a much smaller place during recent decades, and nurses are now very mobile; working all over the world. The shortage of general nurses, which has been noted by the World Health Organisation (WHO), is a major problem for many countries - but when it comes to critical care nurses, it is a huge problem. It seems that there is a constant fight going on; a free-for-all struggle to attract the most competent critical care nurses from 'across the borders'. But how do we judge the level of competence and education of critical care nurses, when we do not have a common benchmark? As far as EfCCNa is aware, there is no European standard of critical care education in existence.

In the year 2000 the European Commission published a report entitled Study of Specialist Nurses in Europe, ${ }^{1}$ which although it only covered member countries of the European Union, provided some useful information. The report does not deal with general nurses, but concentrates on the specialist nurse. One interesting observation was that some countries provide an educational pathway for nurses to qualify, not as general nurses but for more specific specialist nursing duties; so-called branch nurses. Whereas most countries have a general nurse education programme, supported by a range of specialist post-basic courses. The report underlined the fact, that there is a big difference among both general and specialist nurse education within the European Union (EU). An additional complicating factor is that some countries, such as Belgium and Germany, specify the educational content of nursing programmes in Law.

1 Available from the EEC: European Commission (2000). Study of Specialist Nurses in Europe. Reference XV/98/09/E.
One of the goals of the EU is to enable professionals such as nurses, freedom of movement and employment across Europe. To achieve this ambition it would seem a logical necessity for all the countries of Europe to agree common standards of education. However, this is by no means an easy task, and it is one that the European Network of Nursing Organisations (ENNO) has already struggled with in relation to specialist nurses.

The first part of the process towards achieving the goal of common standards of education is to establish what is currently being provided. The EU specialist study has already provided some information, but was limited to member countries of the EU.

\section{AIM OF THE SURVEY}

The EfCCNa Education Sub-committee undertook the study. The aim of the survey was to gather information about critical care education within the member countries of EfCCNa.

When the sub-committee met for the first time, it became obvious that developing a questionnaire would not be an easy task; in the design phase we got a broad hint of the many differences between the various critical care education programmes. Also, whilst developing the questionnaire it became apparent that there was not universal consensus about the terms critical care nurse and intensive care nurse; the terms seemed to be used indiscriminately. For the purposes of this study, when asking about critical care courses, we clarified four areas: intensive care; trauma care; accident and emergency; and anaesthesia.

\section{FINDINGS}

Seventeen countries participated in the survey: Austria, Belgium, Denmark, France, Germany, Greece, Hungary, Iceland, Italy, Norway, Slovenia, Spain, Sweden, Switzerland, The Netherlands, Turkey, United Kingdom. Each member of the Council of Representatives answered the questions on behalf of their country, and all seventeen questionnaires were returned duly completed.

Fifteen countries offered critical care courses and only two did not - Iceland and Greece.

Of those fifteen, several countries had more than one critical 
care course corresponding to the four speciality areas identified above. Not surprisingly, nurses had to be a registered to undertake a specialist course. In addition to being a registered nurse, eight countries had further guidelines with respect to accessing a critical care course (Norway, UK, Denmark, Slovenia, Italy, Hungary, Austria, Germany). Examples of these were recommendations such as clinical experience from an ICU, special abilities and motivation, (up to) two years' experience on a general ward, or an entrance examination.

We asked specifically whether there was a requirement of nurses for a minimum length of practice/clinical experience before registering a critical care course. Answers ranged from 0-36 months (see Figure 1).

Respondents were also asked about the level of qualifications nurses were required to have before working in a critical care unit. Only two countries - Sweden and The Netherlands - required specific critical care education. In the remaining fifteen countries it was possible to work in a critical care unit as a registered nurse, without critical care education. However, Hungary required a minimum of one year's general experience. The reasons for employing nurses without a critical care education are yet unknown, but the shortage of nurses could be one the reasons.

In only five countries (Denmark, Germany, Slovenia, Switzerland, and The Netherlands) was it a public duty to finance the critical care education. In most countries, the expenses were shared equally between hospitals, community authorities or the governments and the nurses themselves. Whether this has an influence on the number of nurses educated in specialities, is an interesting question, which was not addressed in this survey. In one country, medical companies financed elements of the courses, and in no countries did critical care associations fund courses.

Slovenia, Hungary and Spain were the only countries, where the critical care courses were provided only in university hospitals. In the other countries, the courses took place in both university and non-university hospitals and at non-university nursing schools.

The qualifications offered on completion of a critical care course varied. In Norway, Sweden, Spain and Austria one acquired a diploma in critical care nursing. Nurses from Hungary, Switzerland and Germany became registered critical care nurses while the rest of the countries offered a certificate in critical care nursing. As noted above, general nurse education is under reconstruction in many countries, and as far as we know, this is affecting critical care courses, too. In Iceland and Germany for instance, critical care nursing education is being developed at master's level.

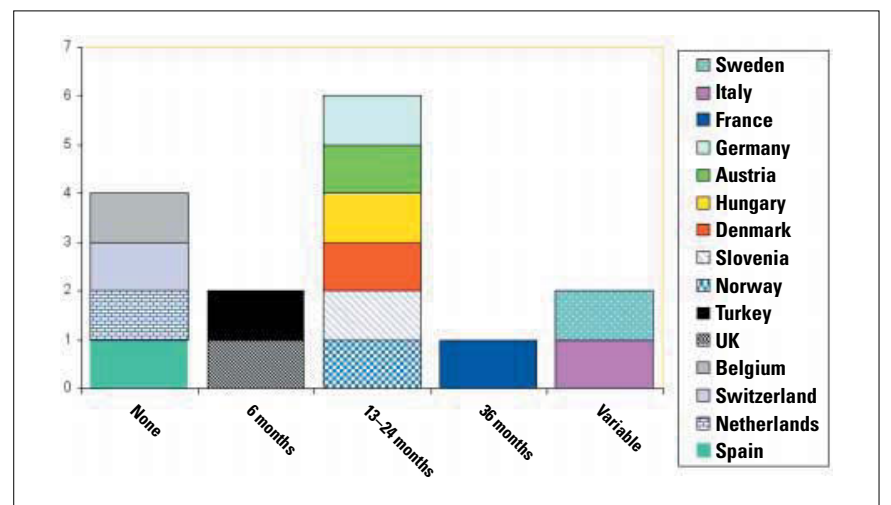

Figure 1. Length of experience required before undertaking a critical care

\section{Teaching}

Not so many years ago, doctors delivered most nursing education. It was a pleasant surprise to learn that this has changed dramaticalIy. In Iceland, Norway, Slovenia, Spain, and UK it is mainly nurses who teach the critical care nurse-students. In the other countries nurses and doctors shared it equally.

Apart from three countries (Turkey, Iceland and Belgium), clinical educators or clinical nursing teachers are permanently employed in many critical care units. Education in practice is obviously given high priority and seems to be in good hands. The demands made on the clinical nursing teachers are very similar. To be a clinically-based critical care nursing teacher, all countries require a degree, a diploma or a certificate in teaching. Teaching qualifications were essential. However, critical care education and/or critical care experience, surprisingly, were not required in several countries.

Teaching new staff is one of the main functions of clinical educators. Another very important role is supervision. Several countries highlighted the importance of purposeful development of attitudes, practical skills and knowledge. The educator, in many cases, was also the key person responsible for designing, planning and delivering the critical care curriculum. A few countries also mentioned research in critical care as a part of an educator's job. Finally, organising 'refresher' courses for critical care nurses was an important task, too.

\section{Salary}

One issue that nurses all over the world always pays attention to, is the salary - and critical care nurses are no exception! In eleven countries successful completion of a critical care course meant an automatic increase in salary. In four countries this was not the case (Belgium, Italy, Spain and UK). However, it was highlighted that in the UK, for example, although nurses did not automatically receive a pay rise they could use a critical care course to apply for promotion, thus increasing their salary.

It is common knowledge that critical care units, not only in Europe, but all over the world are marked by a great turnover of staff. Nurses obviously do not want to work in critical care units forever. But what attracts them to become critical care nurses in the first place? Whilst we recognise that the views of the seventeen respondents in this survey are unlikely to reflect those of thousands of colleagues in their entirety, we did feel it was a worthwhile question to ask.

What we found was that although there was a salary increase in most countries, this was not the main reason nurses moved to critical care. Increased recognition and career prospects ranked among the main reasons. Other reasons are stated in Table 1.

\section{Table 1. Why nurses are attracted to critical care areas}

* To improve knowledge

* Increase of skills and competencies

* Enhancing the quality of care they deliver

* Dynamic work and increased technical skills

* Increased responsibility

* Greater professional power

* Increased recognition and respect

* Better career prospects

* Increased salary 


\section{CONCLUSIONS: PUTTING THE SURVEY INTO PERSPECTIVE}

There were many similarities between countries and also quite a few differences. These are highlighted in Table 2. So, whilst the development of a European critical care curriculum might be desirable, realistically it is, as yet, far away.

\section{Table 2. Key findings from the survey}

$*$

Only two countries required nurses to have undertaken critical care education in order to work in a critical care unit

* Two countries have no critical care education at all

* The level of critical care education is variable ranging from basic certificate to master's level

* Entry requirements for a critical care course are variable

* The practical experience required before commencing a critical course ranged from 0 to 36 months

* The educational content of critical care courses is delivered by nurses or by nurses and doctors equally

* In most countries, nurses must contribute to their education costs

* In all but three countries, critical care units normally have clinical educators permanently employed

* The qualifications required to become a clinical educator in critical care is normally at diploma or degree level. However, it is not always necessary to have critical care specific experience and/or education

* The role of the clinical educator is similar in most countries

* In most countries, completing a critical care course will normally be rewarded with an increase in salary

* Improved knowledge, career prospects, increased skills and competencies, enhanced quality of care, and a formalised education are key factors in motivating nurses to become a critical care nurse

It seems that the findings of this small survey lead to far more questions than it gave answers. We still know very little of the details of critical care courses within the EfCCNa countries. Further work should be undertaken to determine such things as details about the length of the various courses, how many hours of theory and practice they contain, admission requirements, and what competencies and outcomes are expected. There are also many other countries in Europe from whom we have no information - particularly the eastern block.

We did not ask which institutions provided critical care edu- cation. However, informal feedback from European colleagues indicates that the nursing profession across Europe is upgrading its educational status, with most courses being provided by universities. In more and more countries nurses are undertaking bachelor's degrees.

Another interesting topic for discussion, raised by this survey, is the term critical care nurse. If Europe aspires to standardise critical care education then a consensus about what we mean by critical care must be achieved. This is by no means an easy task.

Realistically, at this point in Europe's development, it does not make sense to talk about standardisation of critical care education without first considering standardisation of general nurse education. The Study of Specialist Nurses in Europe referred to in the introduction does its best to describe how nurses can move from state to state in Europe. The report suggests that nursing professions in member states of the EU should be viewed as a single entity. At the same time, the report also notes the reality that currently this is not the case; every country has its own set of rules.

The report states that Europe operates with three different types of registered nurse:

branch nurse (for example, paediatric, mental health
nurses)
general nurse
general nurse with specialist training (for example,
critical care nurses).

The report also concludes that the regulations for moving between member states are not clear and are hard to follow. And, when looking at the inconsistencies we have found in critical care education in the seventeen EfCCNa countries, perhaps it is easy to see why?

So, why are all these deliberations about critical care nursing education necessary? And why does the European Commission publish a report of more than 500 pages that describes specialist nurse education within the European Union? Clearly, nurses want to deliver high-quality nursing and the patients expect high quality nursing wherever in the world they are. Thus it makes sense to standardise nursing education, which enables both a common standard of practice and a mobile workforce.

\section{ACKNOWLEDGEMENTS}

The sub-committee wish to thank John Albarran and Paul Fulbrook from the UK for their help and support with the questionnaire. 